Research Article

\title{
Vibration Induced by Moving Cranes in High-Tech Buildings due to Rail Pad Materials
}

\author{
S. H. Ju (D, H. H. Kuo, and S. H. Ni \\ Department of Civil Engineering, National Cheng-Kung University, Tainan City, Taiwan \\ Correspondence should be addressed to S. H. Ju; juju@mail.ncku.edu.tw
}

Received 1 September 2018; Revised 2 October 2018; Accepted 9 October 2018; Published 3 December 2018

Academic Editor: Chengzhi Shi

Copyright ( 92018 S. H. Ju et al. This is an open access article distributed under the Creative Commons Attribution License, which permits unrestricted use, distribution, and reproduction in any medium, provided the original work is properly cited.

\begin{abstract}
In this work, an appropriate rail pad is proposed to reduce the vibration induced by moving cranes near the source location in high-tech buildings. Using a simple two-degrees-of-freedom model and laboratory experiments, we found that a low-cost rubber pad is effective to reduce crane-induced vibration. A number of finite element analyses with the full model are then performed for a high-tech factory and a moving crane. The results show that a decrease in the stiffness of the rail pad can decrease crane-induced vibration, and it is obvious that the proposed low-stiffness rubber rail pad with significant damping is an appropriate material to reduce crane-induced vibration by as much as five $\mathrm{dB}$. In addition, the displacement field using the rubber pad is still much smaller than $2 \mathrm{~mm}$, which is the working requirement for moving cranes.
\end{abstract}

\section{Introduction}

Moving crane-induced vibration is the major source causing harm to the production in high-tech buildings, where the rail pad that connects the rail and building floor may affect the magnitude of vibrations transmitting from the crane to the floor. Thus, it is important to understand the vibration behavior related to the stiffness and damping effects of such rail pads. However, in the case of high-tech industries, this topic is absent in the literature although several papers have discussed schemes to reduce the slab vibration of railway stations. Grootenhuis considered the disturbance of noise and vibration caused by railways running through a residential area and found that floating track slabs can eliminate the train-induced vibration but that resonance should be avoided [1]. Choi et al. investigated an active vibration control of a translating tensioned steel strip in the zinc galvanizing line, while the effectiveness of the control laws proposed was demonstrated via simulations [2]. Hussein and Hunt discussed modelling of floating-slab tracks on rigid foundations. There were two continuous resilient layers in the model: one to account for the rail pads between the rails and slab and the other to account for slab-bearings underneath the slab [3]. Dere presented a case study evaluating the effectiveness for mitigating ground-borne vibration and noise using a floating-slab track system, which was found to be quite successful in regard to absorbing vibrations, and the noise level was reduced up to $26 \mathrm{~dB}$ after replacing the new rail system [4]. Sheng et al. used revised equations to investigate the dynamics of a typical high-speed railway track, including the dispersion curves of the track, the responses of the rail and slab to a moving harmonic load, and the vibration decay rate along the rail. There have been a number of studies on decreasing railway systems vibration [5]. Wu and Thompson used the theoretical models that describe the high-frequency dynamic behavior of railway track to study the effects of the presence of multiple wheels on the rail, and the results showed that the track noise would be overpredicted for the track with soft pads [6]. Kargarnovin et al. studied the ride comfort of highspeed trains passing over railway bridges. A parametric study was carried out using a time domain model. The effects of damping and the stiffness of the suspension system were investigated [7]. Mirza et al. described the modelling and durability assessment of an elastomeric component used in rail vehicles. The components and structures were modelled using a finite element analysis, and the fracture mechanics parameters were obtained and used to calculate fatigue life [8]. 
Tran et al. proposed the moving element method to investigate the dynamic response of a high-speed rail traveling at nonuniform speeds. A new and exact formulation for calculating the generalized mass, damping, and stiffness matrices of the moving element was proposed [9]. Han et al. suggested cell-hinged, segment-hinged, and identically hinged periodic beam-foundation systems. The frequency dispersion relation and frequency response of these systems with a soil foundation were analyzed, and it was shown that the existence of hinges helps greatly with regard to obtaining both lower and wider band gaps with stronger attenuation [10]. Affolter et al. suggested an improved rail profile, and an analytical proof of the rail fatigue strength was performed, which additionally took into account the local stresses from the finite element simulation [11]. SolSanchez et al. discussed the problems associated with track stiffness, geometry degradation, and vibrations, and they proposed a set of recommendations and guidelines for the use of elastic elements in railway infrastructure [12]. Jin et al. analyzed full-surface supporting, linear supporting, and point-like supporting, and based on laboratory tests, they found that the linear supporting form and the pointlike supporting form have a smaller first resonant frequency than the full-surface supporting form, which is induced by the weakened supporting stiffness [13]. Gautier studied the slab track for trains with very high speeds and presented optimization potentials with respect to existing concepts [14]. Lei and Jiang developed a model for dynamic analyses of a steel spring floating-slab track using finite elements. The results showed that the stiffness and the damping of the isolator are the governing factors, whereas the stiffness and the damping of the rail pad are generally not important. Due to the large deflection from the isolator, this result may not be used to the cranes moving on the high-tech building [15]. Carrascal et al. studied the influence of the sand on the dynamic behavior of the fastening system. Results indicated that the presence of sand in the fastening system generates wear on the sleeper and increases the stiffness after the fatigue test [16]. Wei et al. determined the nonlinear stiffness of thermoplastic polyurethane elastomer rail pads using experiments and finite element analyses. The results showed that the nonlinear amplitude- and frequency-dependent stiffness of rail pads should be taken into account in prediction of environment vibrations due to low-speed railway [17]. Ling et al. presented an investigation into the dynamic behavior of an embedded rail track coupled with a tram vehicle in time domain, and results indicated that the embedded rail track has advantages over the fastened slab track to reduce the dynamic contact force, the vibration level, and deformation of the track parts [18]. Oregui et al. presented a sensitivity analysis of rail pad parameters on vertical railway track dynamics, and they found that rail pad type, toe load, and aging are identified as the most relevant parameters in the frequency range of $300-3,000 \mathrm{~Hz}$ [19].

High-tech buildings often move products using rail-track systems because such systems are efficient and automatic, but vibration induced by moving vehicles will cause problems. Although there have been many investigations of railway systems to decrease the vibrations induced by moving vehicles, there are rare researches directed toward high-tech buildings. The structural system of high-tech buildings is much more complicated than that of railway stations, and the relationship between the critical vibration and frequency range of the two is different, one for the machine and the other for the human. Therefore, a detailed numerical simulation of high-tech building vibration is necessary. This study thus investigates the reduction of moving crane-induced vibration in a high-tech building using an appropriate rail pad. Simple equations and laboratory experiments were performed initially to select a suitable pad material, and complicated finite element models were then analyzed to complete the parametric study.

\section{Discussion of a Rail Pad Effect Using a Simplified Equation and Experiments}

2.1. A Simplified Two-Degrees-of-Freedom Model to Determine the Rail Support Effect. A crane moves on a rail and thus produces vibrations that are transmitted from the rail pad to the building floor. In this section, we use a twodegrees-of-freedom model to find the stiffness and damping effects of a rail pad with the goal of reducing such vibrations. The dynamic equation is as follows:

$$
\begin{gathered}
{\left[\begin{array}{cc}
M_{1} & 0 \\
0 & M_{2}
\end{array}\right]\left\{\begin{array}{c}
\ddot{x}_{1} \\
\ddot{x}_{2}
\end{array}\right\}+\left[\begin{array}{cc}
C_{1} & -C_{1} \\
-C_{1} & C_{1}+C_{2}
\end{array}\right]\left\{\begin{array}{c}
\dot{x}_{1} \\
\dot{x}_{2}
\end{array}\right\}} \\
+\left[\begin{array}{cc}
K_{1} & -K_{1} \\
-K_{1} & K_{1}+K_{2}
\end{array}\right]\left\{\begin{array}{l}
x_{1} \\
x_{2}
\end{array}\right\}=\left\{\begin{array}{c}
P \sin (2 \pi f t) \\
0
\end{array}\right\},
\end{gathered}
$$

where $f$ is the frequency $(\mathrm{Hz})$ of the load, $P$ is its magnitude, $M_{2}, C_{2}$, and $K_{2}$ are the equivalent mass, damping, and stiffness, respectively, of the building floor at the rail pad location, and $M_{1}, C_{1}$, and $K_{1}$ are those of the rail pad. The $M_{2}, C_{2}$, and $K_{2}$ of the building floor were used to model the parameters of the complicated floor, and we approximately estimated them from an impact hammer experiment, where a force sensor on the hammer and two acceleration meters on the floor to find the floor stiffness, the stiffness Rayleigh damping is assumed 1/1000, and the floor area is set to $600 \mathrm{~m}^{2}$ with the mass of $1.67 \mathrm{t} / \mathrm{m}^{2}$. Thus, we set $f, P, M_{1}, M_{2}, K_{2}$, and $C_{2}$ equal to $28 \mathrm{~Hz}, 1 \mathrm{kN}, 10 \mathrm{t}, 1000 \mathrm{t}$, $3 \mathrm{E} 6 \mathrm{kN} / \mathrm{m}$, and $300 \mathrm{kN} \cdot \mathrm{s} / \mathrm{m}$, respectively, and changed $K_{1}$ and $C_{1}$ to obtain the results, as shown in Figure 1, where these data are approximately calibrated from the analyzed high-tech building mentioned in Section 3.2. This figure indicates that when a small amount of rail pad stiffness is used, appropriate rail pad damping can considerably reduce craneinduced vibration. However, significant rail pad stiffness may cause a large amount of crane-induced vibration, which is independent of the rail pad damping. Thus, the issue left is to find a suitable material for the rail pad that can reduce the crane-induced vibration but does not produce too much crane displacement, which violates the deformation requirements for a moving crane. In the next section, an experiment is discussed to validate that rubber can be a suitable material for the rail pad, and Section 3 discusses the finite element analysis used to investigate the above issue. 


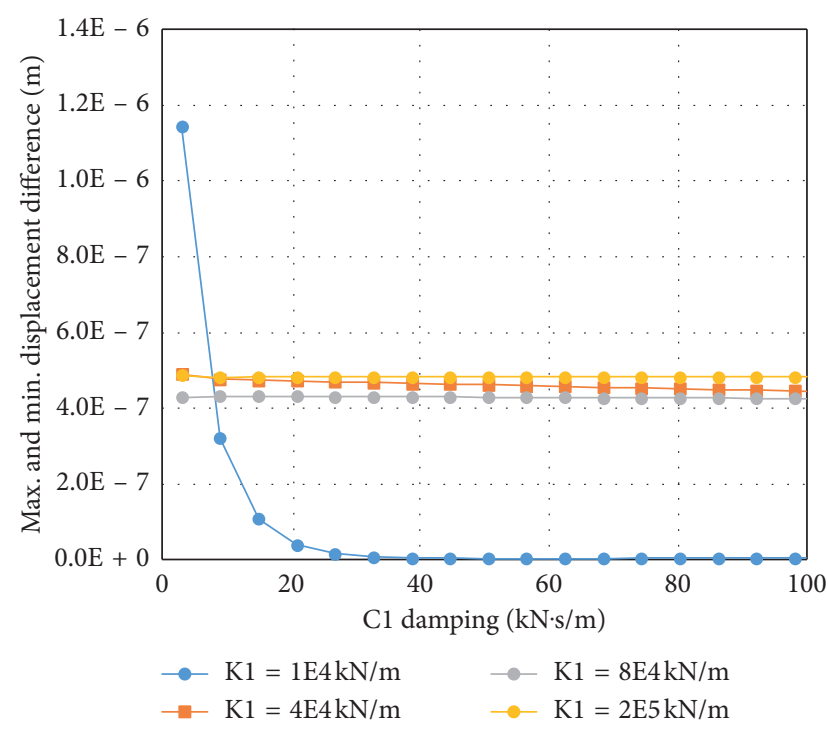

FIgURE 1: The slab vibration changing with the rail stiffness $\left(K_{1}\right)$ and damping $\left(C_{1}\right)$ using the two-degrees-of-freedom model.

2.2. The Stiffness and Damping of the Rubber Rail Support. The laboratory experiments, as shown in Figure 2 for the setup, were used to find the stiffness $k$ and damping $c$ of the rubber pad for the rail support while the sine wave load was used. The experiment can be simulated as a single-degree-offreedom model using the following equation:

$$
k d+c \dot{d}=F \sin \omega t,
$$

where $d$ is the displacement, $F$ is the amplitude of the applied force, and $\omega$ is the load frequency. The solution for this equation is

$$
d=a \sin \omega t+b \cos \omega t
$$

where

$$
\begin{aligned}
& a=k F /\left[(c \omega)^{2}+k^{2}\right], \\
& b=-c \omega F /\left[(c \omega)^{2}+k^{2}\right] .
\end{aligned}
$$

The stiffness $k$ can be obtained by fitting the experimental data using a straight line regulation. The difference in the displacement at the applied mean load, as shown in Figure 3 , is used to find the pad damping, which will produce an equation as follows:

$$
B(c \omega)^{2}-A(c \omega)+B k^{2}=0,
$$

where $B$ and $A$ are the average differences in the displacement and force of the experimental data, as shown in Figure 3 . The pad damping $c$ can be obtained by solving the above equation.

Figure 2 shows the experimental setup and a specimen of the $1 \mathrm{~cm}$ thick, $6 \mathrm{~cm}$ by $6 \mathrm{~cm}$ rubber pad. Cyclic load control at a fixed frequency was performed in the experiment, and Figure 3 shows the experimental results under the load frequencies of 20 and $25 \mathrm{~Hz}$. Next, equations (2) to (5) were used to find the best-fit stiffness $(k)$ and damping $(c)$ from the experimental results, and the best-fit curves are also

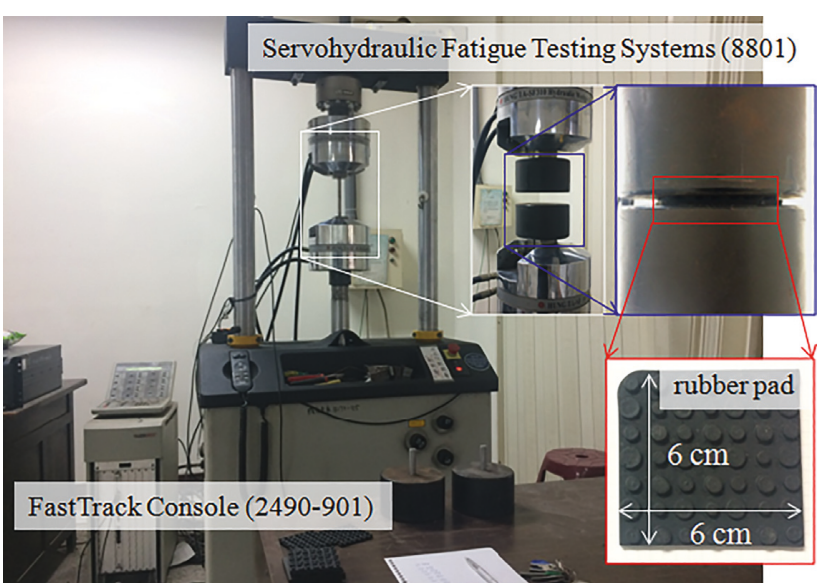

Figure 2: Experimental setup and the $6 \mathrm{~cm}$ by $6 \mathrm{~cm}$ rubber pad specimen.

shown in this figure indicating good agreement. This figure shows the damping of the rubber specimen to be approximately $14 \mathrm{kN} \cdot \mathrm{s} / \mathrm{m}$, and the stiffness is about $0.9 \mathrm{E} 4 \mathrm{kN} / \mathrm{m}$, and these data, as shown in Figure 1, produced good efficiency to reduce the floor vibration. Further studies are performed using the finite element analysis of a full factory model with a moving crane, as shown in Figure 4.

\section{Finite-Element Parametric Studies}

3.1. Vibration Standard Using the One-Third Octave Band. The vibration based on the one-third octave band is used in this paper, while the power spectrum density is

$$
S_{\mathrm{y}}(f)=\frac{2|Y(f)|^{2}}{T}
$$

where $f$ is the frequency $(\mathrm{Hz})$ and $|Y(f)|$ is the fast Fourier transformation amplitude from a selected velocity record $y(t)$ with the time interval of $T$. Then, the root mean square velocity level $L_{\mathrm{y}}\left(f_{\mathrm{c}}\right)$ is computed in decibels $(\mathrm{dB})$ :

$$
L_{\mathrm{y}}\left(f_{\mathrm{c}}\right)=20 \log _{10} \frac{\sqrt{\int_{f_{1}}^{f_{\mathrm{u}}} S_{\mathrm{y}}(f) d f}}{\sigma_{0}},
$$

where $f_{1}, f_{\mathrm{u}}$, and $f_{\mathrm{c}}$ are lower band, upper band and center frequencies, respectively, and the referred velocity $\sigma_{0}=1 \mathrm{E}-6$ in $/ \mathrm{s}(2.54 \mathrm{E}-8 \mathrm{~m} / \mathrm{s})$. Equation (7) is frequency-dependent, and one can obtain $L_{\mathrm{y}}\left(f_{\mathrm{c}}\right)$ from each frequency to obtain the frequency-independent vibration total $\mathrm{dB}$ :

$$
\mathrm{dB}_{\text {total }}=10 \times \log _{10}\left(\sum_{f_{\mathrm{c}}}^{\leq 100 \mathrm{~Hz}} 10^{0.1 \times L_{\mathrm{y}}}\left(f_{\mathrm{c}}\right)\right) .
$$

In this study, the particle velocities were obtained either from the experiment or finite element analysis, where $T$ in equation (6) was set to $8 \mathrm{~s}$ and was shifted to $1 \mathrm{~s}$ to select another $8 \mathrm{~s}$. The maximum one-third octave band results can then be obtained from all $8 \mathrm{~s}$ data.

3.2. Structural and Finite Element Model of High-Tech Buildings. For high-tech factories, the superstructures with 

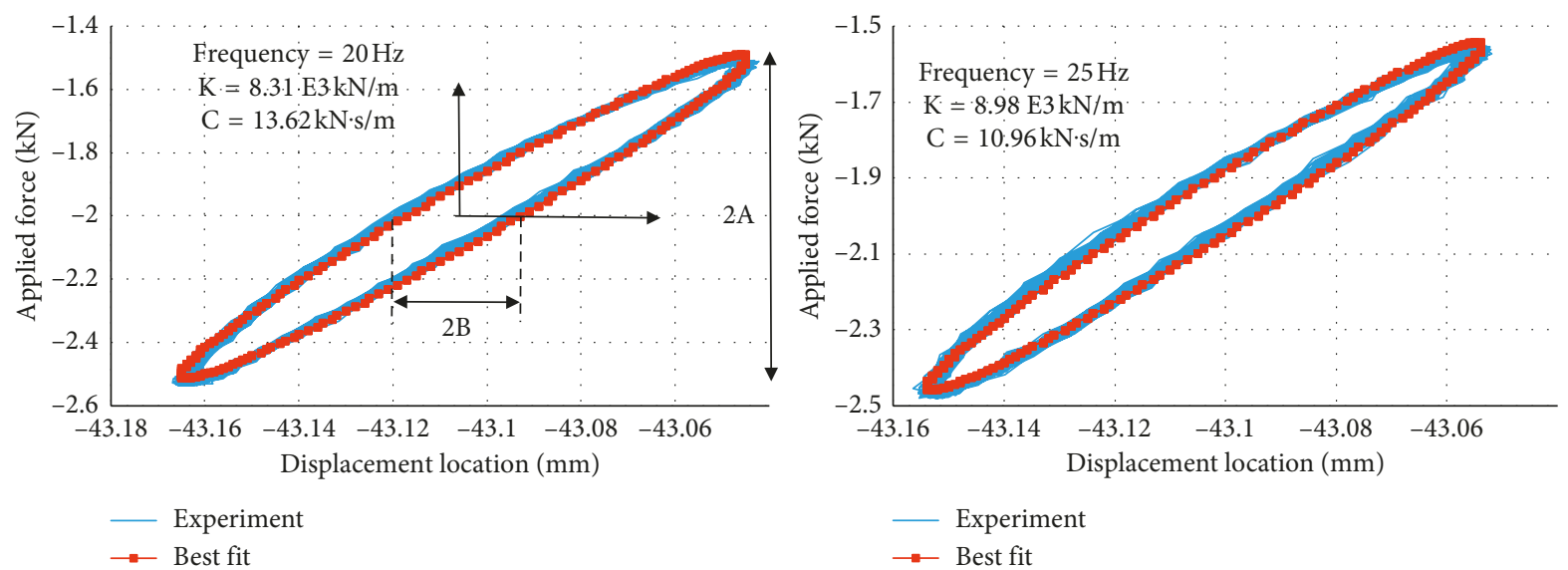

Figure 3: Experimental and best-fit (equations (2) to (5)) results for the rubber pad at 20 and $25 \mathrm{~Hz}$.
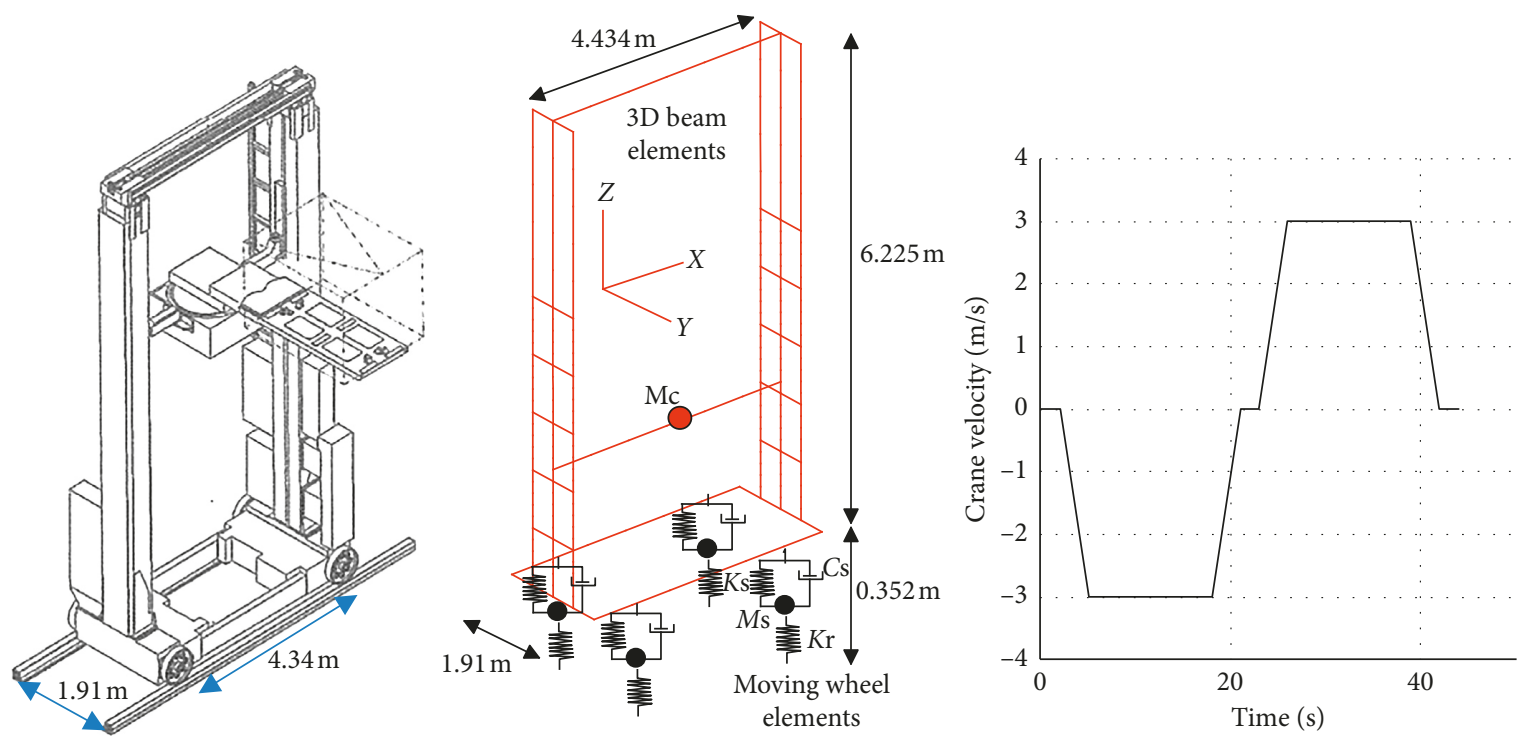

Figure 4: Dimensions, speed, and finite element model of the moving crane used in this study $(M c=2 \mathrm{t}, M s=0.9 \mathrm{t} K r=0.4 \mathrm{E} 5 \mathrm{kN} / \mathrm{m}, K s=$ $1.2 \mathrm{E} 5 \mathrm{kN} / \mathrm{m}$, and $C s=1 \mathrm{kN} \cdot \mathrm{s} / \mathrm{m}$ ).

long-span steel trusses are required, and dense reinforced concrete (RC) columns with thick slabs are constructed to reduce microvibration. In this study, a three-story building was analyzed, and the vibration of the second floor will be investigated, where the first story is the RC structure with dense columns and other two are large-span steel truss structures. Figure 5 shows two typical frames in the $X$ and $Y$ directions, where the steel column spacing is $32 \mathrm{~m}$ and $12 \mathrm{~m}$, respectively. The square $\mathrm{RC}$ column size is $0.9 \mathrm{~m}$, and the RC slabs are 0.55 deep for the second floor and $0.45 \mathrm{~m}$ for the third floor. The slabs contain $0.4 \mathrm{~m}$ diameter circular holes with the interval between two hole centers of $0.7 \mathrm{~m}$. The steel sections of the second story are listed in Table 1.

\subsection{Finite Element Model of Moving Cranes and Rail Pads.} As shown in Figures 4-6, the crane moving on the second floor (the first steel truss floor) contains four wheels, a loading frame, and a product support. It was modelled as the combination of four moving wheel elements, four threedirection spring-damper elements for the loading frame, a space frame with a member size of $100 \mathrm{~mm} \times 100 \mathrm{~mm} \times$ $10 \mathrm{~mm} \times 10 \mathrm{~mm}\left(d \times b_{\mathrm{f}} \times t_{\mathrm{w}} \times t_{\mathrm{f}}\right)$, and a lumped mass of $2 \mathrm{t}$ for the product support. The finite element models of the spring-damper and moving wheel elements are modified from the literature [20] to combine with the flexible frame of the crane and the rail on the high-tech factory, as shown in Figure 6. For the moving wheel element, the three-node element stiffness for the nodal displacements $\left(d_{1}, \theta_{1}, d_{2}, d_{3}\right.$, $\theta_{3}$ ) is as follows:

$$
\begin{aligned}
\mathbf{S}_{\mathrm{W}} & =T^{\mathrm{T}}\left[\begin{array}{rr}
k_{\mathrm{r}} & -k_{\mathrm{r}} \\
-k_{\mathrm{r}} & k_{\mathrm{r}}
\end{array}\right] T, \\
T & =\left[\begin{array}{ccccc}
0 & 0 & 1 & 0 & 0 \\
N_{1} & N_{2} & 0 & N_{3} & N_{4}
\end{array}\right],
\end{aligned}
$$

where $k_{\mathrm{r}}$ is the stiffness between the rail and wheel, $d_{2}$ is the translation of the wheel node, $d_{1}, \theta_{1}, d_{3}$, and $\theta_{3}$ are the 

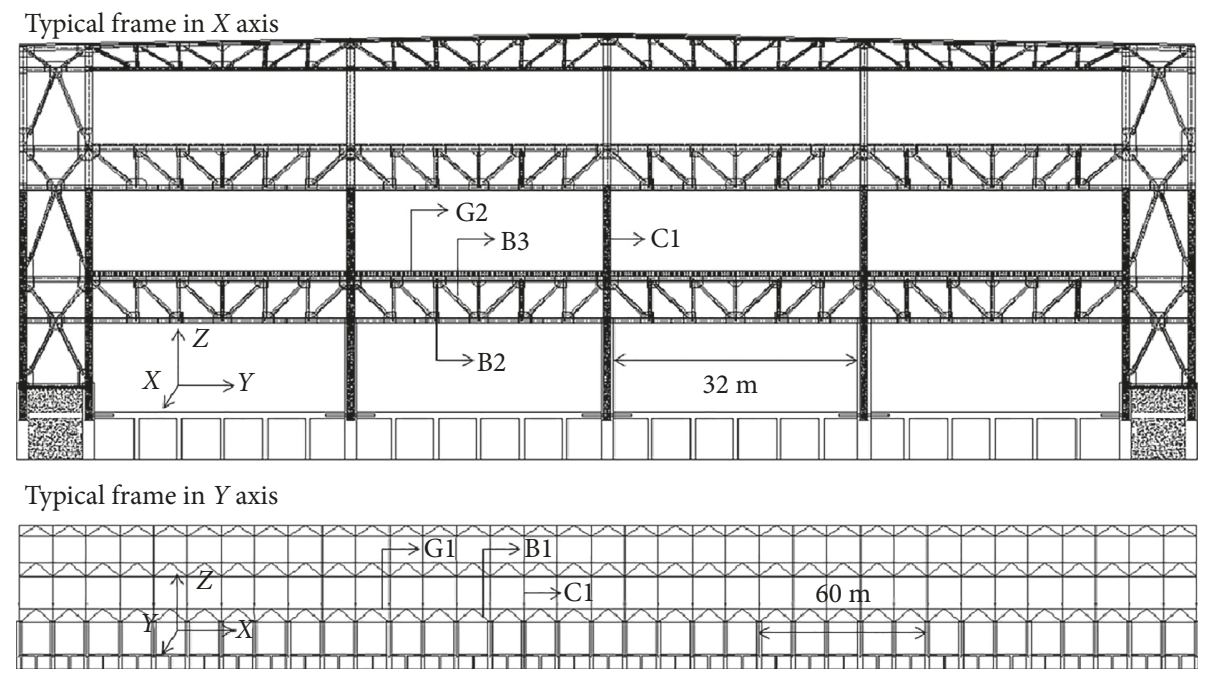

Figure 5: Two typical frames in the $X$ and $Y$ directions.

TABLE 1: The steel sections of the 2nd story of the analyzed high-tech factory.

\begin{tabular}{|c|c|c|c|c|}
\hline Member & Axis & Label & Member section $(\mathrm{mm}) d \times b_{f} \times t_{w} \times t_{f}$ & Material \\
\hline Steel column & ALL & $\mathrm{C} 1$ & $\square 900 * 900 * 35 * 35$ & A572 GR50 \\
\hline Steel braces & $X$ & B1 & $\mathrm{RH} 400 * 400 * 13 * 21$ & A572 GR50 \\
\hline Steel braces & $Y$ & B2 & $\mathrm{RH} 414 * 405 * 18 * 28$ & A572 GR50 \\
\hline Steel braces & $Y$ & B3 & $\mathrm{RH} 428 * 407 * 20 * 35$ & A572 GR50 \\
\hline Steel girder & $X$ & G1 & RH $588 * 300 * 12 * 20$ & A572 GR50 \\
\hline Steel girder & $Y$ & G2 & BH $375 * 200 * 10 * 25$ & A572 GR50 \\
\hline
\end{tabular}

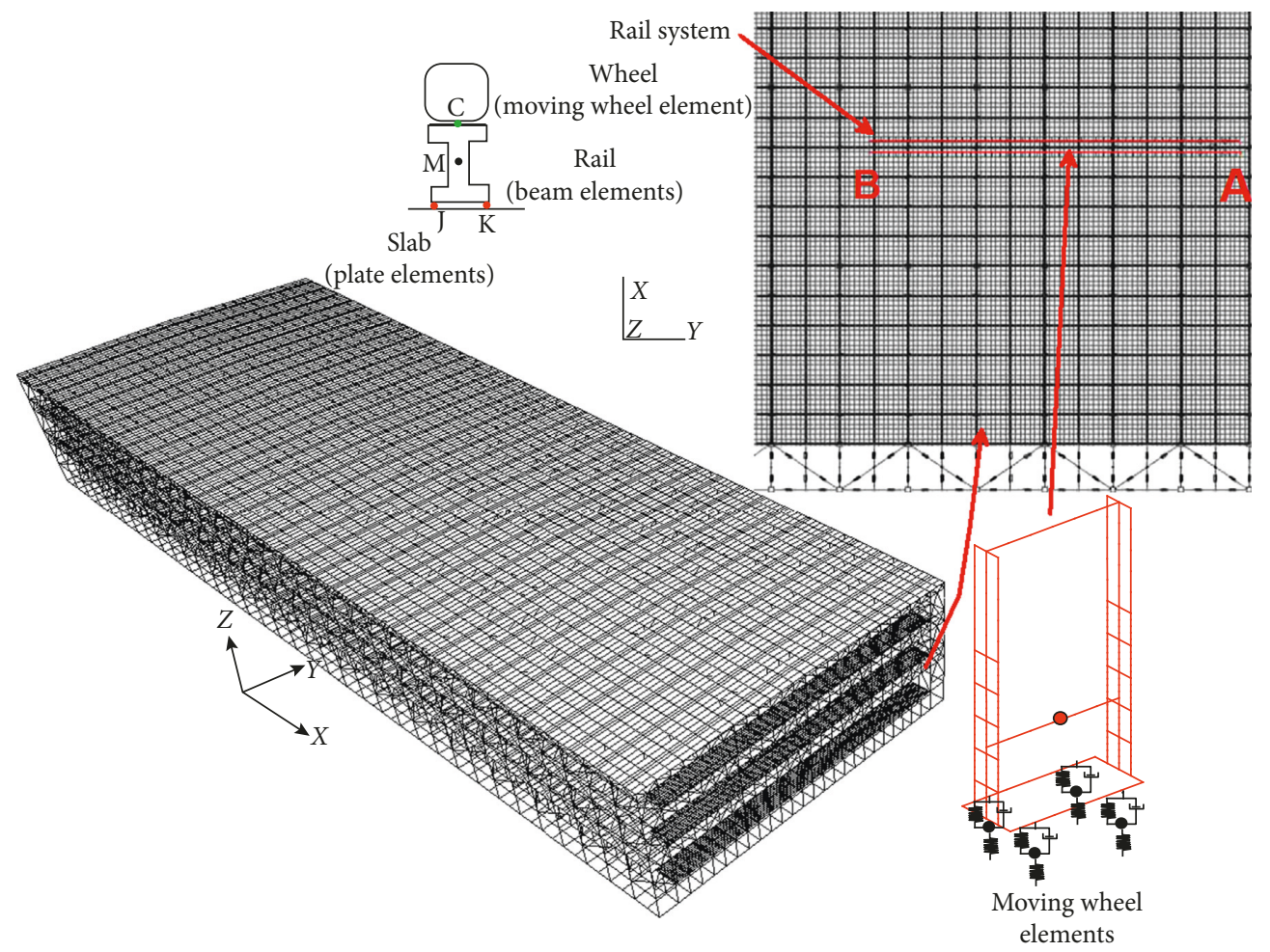

Figure 6: Finite element model including the high-tech factory, rails, crane, and slabs (nodes J, K, and C are slave nodes controlled by the master node M.). 
translations and rotations at target nodes 1 and 3 , and $N_{i}$ is the cubic Hermitian interpolation functions. The internal forces of the wheel elements are

$$
\begin{aligned}
{\left[\begin{array}{lllll}
f_{1} & m_{1} & f_{2} & f_{3} & m_{3}
\end{array}\right]^{\mathrm{T}}=} & \mathbf{S}_{\mathbf{w}}\left[\begin{array}{lllll}
d_{1} & \theta_{1} & d_{2} & d_{3} & \theta_{3}
\end{array}\right]^{\mathrm{T}} \\
& -\left[\begin{array}{lllll}
N_{1} & N_{2} & -1 & N_{3} & N_{4}
\end{array}\right] k_{\mathrm{r}} r_{\mathrm{v}}(X),
\end{aligned}
$$

where $\left(f_{1}, m_{1}, f_{2}, f_{3}\right.$, and $\left.m_{3}\right)$ are internal forces and moments at nodes 1,2, and 3, and the nodal forces should exclude the rail irregularity terms $r_{\mathrm{v}}(X)$. If the contact force $f_{2}$ is positive, the wheel and rail are separated, and $k_{\mathrm{r}}$ is set at zero for the next Newton-Raphson iteration. Otherwise, they are in contact. For a damper or spring linked to two master nodes, the damping or stiffness matrix is

$$
\mathbf{S}=s \mathbf{B B}^{\mathrm{T}} \text {, }
$$

where $s$ is the spring constant for the stiffness matrix $\mathbf{S}$ or the damping constant for damping matrix $\mathbf{S}$ and $\mathbf{B}$ is a vector generated from the coordinate difference between the master and spring-damper nodes.

For the crane acceleration simulation, we assume that all the displacements, velocities, and accelerations for vehicles in the motion direction are relative to the current averaged displacement, velocity, and acceleration. Therefore, the forces at mass locations due to the averaged vehicle acceleration in the motion direction can be calculated explicitly as the inertia forces in the negative acceleration direction. In this study, the crane moves on the railway system on the second floor for a distance of $48 \mathrm{~m}$, then stops at the rightmost side of the rail for $2 \mathrm{~s}$ at the beginning, and then moves in the left direction with an acceleration of $1 \mathrm{~m} / \mathrm{s}^{2}$ to reach the final speed of $3 \mathrm{~m} / \mathrm{s}$. After it moves a specific distance at a constant speed, the crane begins to decelerate at $1 \mathrm{~m} / \mathrm{s}^{2}$. Finally, it stops, and the total moved distance is $48 \mathrm{~m}$. The backward route of the crane is then the reverse of the above procedures. The rail irregularity has an amplitude of $1.5 \mathrm{~mm}$ per $10 \mathrm{~m}$ of the rail in the vertical and transverse directions of the rail, for which the irregularity parameters are shown in Table 2 for both directions using the equations and parameters from Reference [21].

3.4. Finite Element Model of the High-Tech Building and Rail System. Figure 6 shows the three-dimensional finite element mesh, including the high-tech factory, rail system, crane, and waffle slabs, where the total number of degrees of freedom is $1,605,952$. The beams, columns, and trusses were modelled using the 2-node three-dimensional (3D) beam element with the shear deformation effect, and the end release function was used to simulate the truss member. The foundation at each column bottom was simulated using a three-direction spring with a stiffness of $2 \mathrm{E} 6 \mathrm{kN} / \mathrm{m}$ for that connected with a steel column and $1 \mathrm{E} 6 \mathrm{kN} / \mathrm{m}$ for the others, for which these stiffness values were approximately estimated from the averaged soil stiffness of $3 \mathrm{E} 4 \mathrm{kN} / \mathrm{m}^{3}$. The waffle slab with a hole diameter of $0.6 \mathrm{~m}$ and hole interval of $0.7 \mathrm{~m}$ was simulated using the 2 -node $3 \mathrm{D}$ beam element with a $0.4 \mathrm{~m}$ and a $0.18 \mathrm{~m}$ wide rigid zone at both ends of the element. The
TABle 2: Rail irregularity parameters used in the numerical analyses.

\begin{tabular}{lccccc}
\hline $\begin{array}{l}A_{\mathrm{r}} \\
\left(\mathrm{m}^{2} \cdot \mathrm{rad} / \mathrm{m}\right)\end{array}$ & $\begin{array}{c}\omega_{1} \\
(\mathrm{rad} / \mathrm{m})\end{array}$ & $\begin{array}{c}\omega_{2} \\
(\mathrm{rad} / \mathrm{m})\end{array}$ & $\begin{array}{c}\omega_{1} \\
(\mathrm{rad} / \mathrm{m})\end{array}$ & $\begin{array}{c}\omega_{\mathrm{u}} \\
(\mathrm{rad} / \mathrm{m})\end{array}$ & $N$ \\
\hline $0.4 \mathrm{E}-7$ & 0.0 & 2.1 & 0.08 & 150 & 2000 \\
\hline
\end{tabular}

slabs at the bottom levels of the trusses on the second and third stories were modelled using a 4-node plate element. The rail system, located on the $\mathrm{RC}$ floor from point $\mathrm{A}$ to point $\mathrm{B}$, as shown in Figure 6, contained two $I_{\mathrm{x}}=0.19 \mathrm{E}-4 \mathrm{~m}^{4}$ and $I_{\mathrm{y}}=$ $0.6 \mathrm{E}-4 \mathrm{~m}^{4}$ steel rails, with an area of $0.17 \mathrm{E}-2 \mathrm{~m}^{2}$. The 2 -node $3 \mathrm{D}$ beam element was used to simulate the rails, for which the spring-damper element representing the stiffness and damping between rails and slabs was set in the parametric study, where the interval between the supports was $1.3 \mathrm{~m}$. As shown in Figure 6, two slave nodes J and K controlled by the master node $\mathrm{M}$ at the beam center at each support were set, where the two spring-damper elements are connected between the two slave nodes and two slab nodes. A slave node $\mathrm{C}$ at the rail top controlled by the beam master node $M$ at each support was set for the target route of the moving wheel element. The crane model could move on the rail system connected to the high-tech structure. The average acceleration Newton-Raphson method and the consistent mass scheme were used to solve this problem, where the time step length was 0.005 seconds, with 10,000 time steps being simulated.

Figure 7 shows a comparison of the results for the measurements and finite element analysis of velocity $\mathrm{dB}$ at $5 \mathrm{~m}$ from the rail centerline, while the velocity meter was used to record the vibration induced by the crane moving at an average speed of $3 \mathrm{~m} / \mathrm{s}$, as shown in Figure 4 . The springdamper element with a stiffness of $4.8 \mathrm{E} 5 \mathrm{kN} / \mathrm{m}$ and damping of $10 \mathrm{kN} \cdot \mathrm{s} / \mathrm{m}$ was used in the finite element model to simulate the support between the rails and slabs, where the stiffness was calculated from the steel rod supported between the rail and slab, and the damping was estimated using a damping ratio of $1 \%$. The comparison indicated good agreement between the experiment and finite element results. Thus, we used this model to perform the parametric study discussed in the following section. Figure 7 also indicates that the major vibration frequencies are ranging from 15 to $30 \mathrm{~Hz}$, and the reason should be the slab natural frequencies invoked by rail irregularities. For this reason, we showed the experimental results near this frequency range in Figure 3.

3.5. Case Study. The parametric studies included the four finite element analyses changing the rail pad damping to 10 , 20,30 , and $200 \mathrm{kN} \cdot \mathrm{s} / \mathrm{m}^{2}$ for a fixed pad stiffness of $1 \mathrm{E} 4 \mathrm{kN} / \mathrm{m}^{2}$, where the interval of the rail pad is set at $1.3 \mathrm{~m}$. We also set two different intervals for the rail pad $(0.65$ and $0.45 \mathrm{~m})$ for another two finite element analyses using a pad stiffness of $1 \mathrm{E} 4 \mathrm{kN} / \mathrm{m}^{2}$ and damping of $10 \mathrm{kN} \cdot \mathrm{s} / \mathrm{m}^{2}$. The above analysis results, represented as the total velocity $\mathrm{dB}$, are shown in Figure 8. Figure 9 shows the analysis results for the four finite element analyses with a pad stiffness of $1 \mathrm{E} 6 \mathrm{kN} / \mathrm{m}^{2}$ and damping of $10,20,40$, and $200 \mathrm{kN} \cdot \mathrm{s} / \mathrm{m}^{2}$, where the pad 


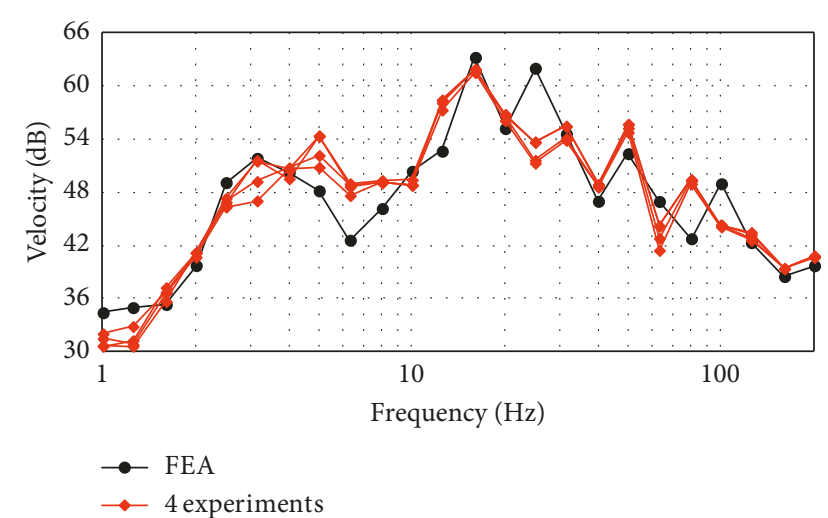

FIGURE 7: Comparison of the velocity $\mathrm{dB}$ between the finite element analysis and four experimental measurements at $5 \mathrm{~m}$ from the rail centerline.

interval was set at $1.3 \mathrm{~m}$. Figure 10 shows the analysis results of the case with pad damping of $10 \mathrm{kN} \cdot \mathrm{s} / \mathrm{m}^{2}$ and stiffnesses of $1 \mathrm{E} 4,4 \mathrm{E} 4,1 \mathrm{E} 5$, and $1 \mathrm{E} 6 \mathrm{kN} / \mathrm{m}^{2}$, where the pad interval was set at $1.3 \mathrm{~m}$. Figure 11 shows the displacement of a point at the rail induced by the moving crane under three different stiffness values, $1 \mathrm{E} 4,4 \mathrm{E} 4$, and $1 \mathrm{E} 5 \mathrm{kN} / \mathrm{m}^{2}$, of the rail pad. These figures indicate the following:

(1) When a low-stiffness rail pad is used, as shown in Figure 8 , the increase in the damping value can effectively decrease the slab vibration. This condition can be obviously observed in Figure 1 as obtained from the simple two-degrees-of-freedom formulation. The stiffness and damping shown in this figure are in the range of the rubber pad, as shown in Section 2.2. Thus, using the rubber rail pad to reduce crane-induced vibration is appropriate. However, when shortening the rail pad interval, such as from $1.3 \mathrm{~m}$ to $0.65 \mathrm{~m}$, the efficiency of the vibration reduction decreases since this condition increases the equivalent stiffness of the rail pad, which in turn reduces the vibration reduction efficiency.

(2) When the rail pad is very stiff, as shown in Figure 9, the slab vibration is almost independent of the rail pad damping. This condition can also be observed in Figure 1, as obtained from the simple two-degreesof-freedom formulation. Since significant rail pad stiffness causes very small relative deformation and velocity between the rail and slab, the material damping has no opportunity to reduce the vibration transmitted from the rail. For this reason, if one uses a stiffer rail pad, such as a steel pad, the damping of the material is not important.

(3) Figure 10 clearly indicates that decreases in the stiffness of the rail pad can also decrease the craneinduced vibration, so a suitable small amount of stiffness should be used. From the laboratory experiments discussed in Section 2.2, it is obvious that rubber is an appropriate material for a rail pad to reduce crane-induced vibrations near the source.

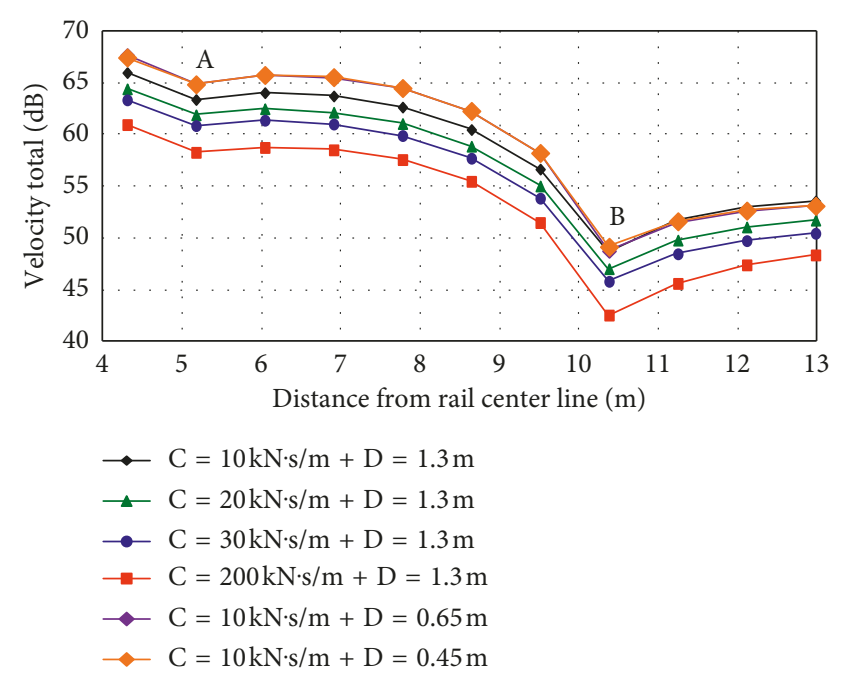

FIGURE 8: Finite element results for the vibration total dB (equation (8)) changing with the distance from the rail centerline under a rail pad stiffness of $1 \mathrm{E} 4 \mathrm{kN} / \mathrm{m}$ (where $\mathrm{C}$ is the rail pad damping and $\mathrm{D}$ is the interval of the rail pad).

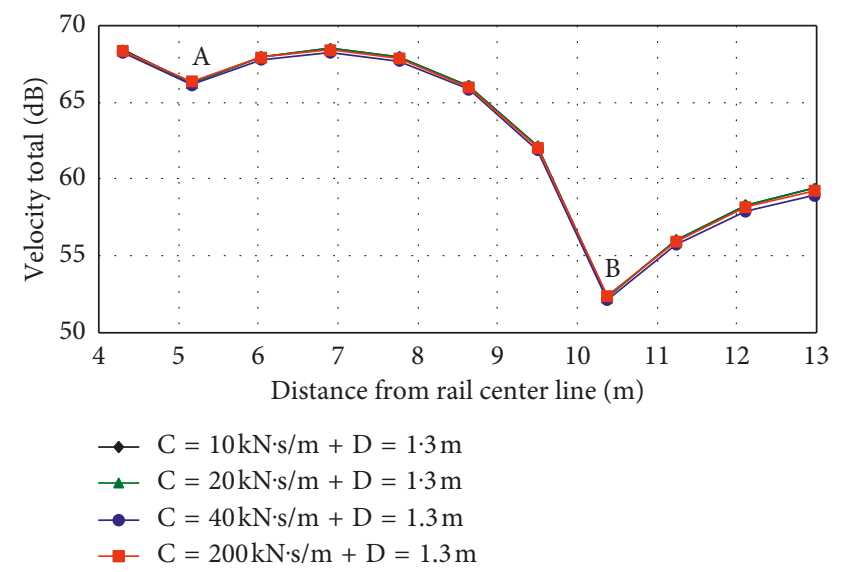

FIGURE 9: Finite element results for the vibration total $\mathrm{dB}$ (equation (8)) changing with the distance from the rail centerline under a rail pad stiffness of $1 \mathrm{E} 6 \mathrm{kN} / \mathrm{m}$ (where $\mathrm{C}$ is the rail pad damping and $\mathrm{D}$ is the interval of the rail pad).

Rubber is not an expensive material, but it can be used to make rail pads that will reduce crane-induced vibration by about 3 to $5 \mathrm{~dB}$. It is noted that one can also increase member sizes or install dampers to reduce this vibration. However, the cost of such alternatives will be much greater than that of the rubber pad to reduce crane-induced vibration by 3 to $5 \mathrm{~dB}$.

(4) In the figures, it is shown that the vibration will be relatively smaller at locations $A$ and $B$ because the two locations have a big girder, where greater stiffness may decrease the vibration. The displacement field shown in Figure 11 indicates that the low stiffness of the rail pad will increase the rail 


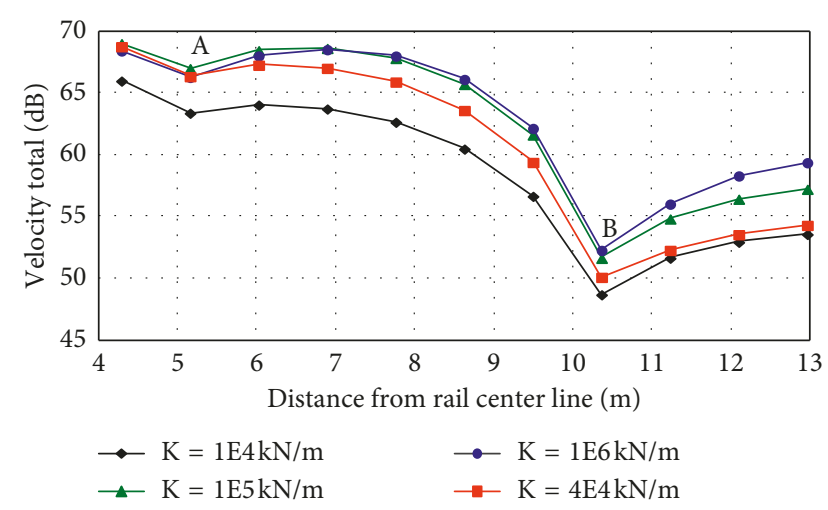

FIgURE 10: Finite element results for the vibration total $\mathrm{dB}$ (equation (8)) changing with the distance from the rail centerline under a rail pad damping of $10 \mathrm{kN} \cdot \mathrm{s} / \mathrm{m}$ (where $K$ is the rail pad stiffness and the rail pad interval is $1.3 \mathrm{~m}$ ).

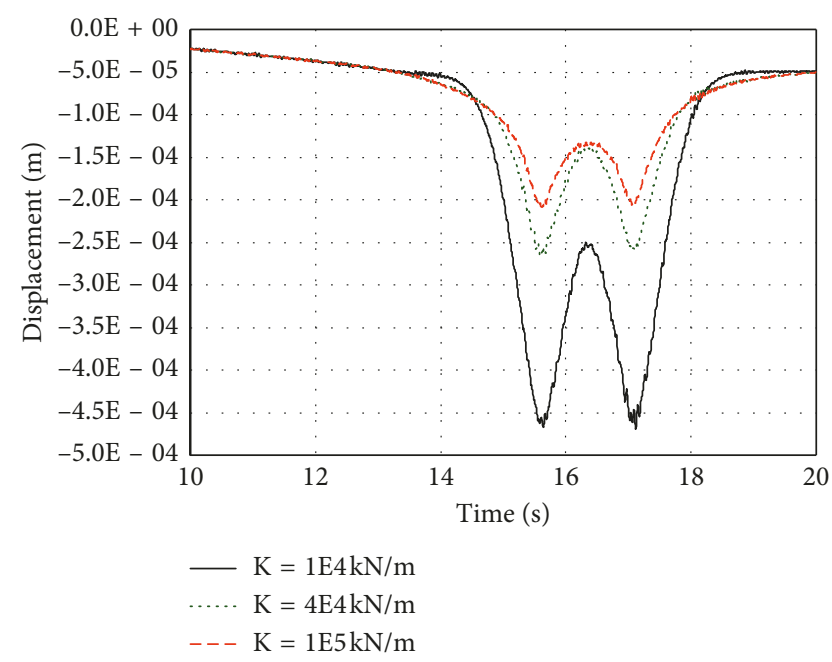

FIGURE 11: Displacement of a point at the rail induced by the moving crane under three different rail pad stiffness values.

displacement induced by the crane load. However, the displacement fields of the three different pads are still much smaller than $2 \mathrm{~mm}$, which is the working requirement for the moving crane.

\section{Conclusion}

High-tech buildings often make use of automatic vehicles or crane systems to carry products rapidly, but these moving systems produce vibrations that harm high-tech processes. This paper thus discusses how to reduce moving craneinduced vibration using an appropriate rail pad. First, a simple two-degrees-of-freedom system is used to model the factory slab and the crane rail system, and the result shows that when the stiffness of the rail pad is reduced, an increase in the damping value can effectively decrease the slab vibration. However, when a significant rail pad stiffness is used, the slab vibration is almost independent of the rail pad damping, and the vibration reduction cannot be high. Laboratory experiments were conducted to determine the stiffness and damping of the rubber pad, for which the results indicated that using the rubber rail pad to reduce crane induced vibration is effective. Finally, a number of finite element analyses with a full model of a high-tech factory and moving crane were performed. The results indicate that decreases in the stiffness of the rail pad can also decrease crane-induced vibration, and it is obvious that the rubber rail pad with low-stiffness and high-damping properties is an appropriate material to reduce craneinduced vibration. Moreover, the displacement field using the rubber pad is still much smaller than the $2 \mathrm{~mm}$ moving crane working requirement. The rubber material is not expensive, and it can be used to make rail pads that reduce crane-induced vibration by approximately 3 to $5 \mathrm{~dB}$. It is noted that one can also increase member sizes or install dampers to reduce this vibration. However, the cost will be much greater than that for the rubber pad to reduce craneinduced vibration in a range of 3 to $5 \mathrm{~dB}$. The rubber rail pad damps the vibration just near the vibration source, so the efficiency should be high. However, when the vibration has been spread out, the reduction of crane-induced vibration will be more and more difficult. The layout of high-tech buildings is often similar with floor stiffness ranging from $2 \mathrm{E} 6$ to $6 \mathrm{E} 6 \mathrm{kN} / \mathrm{m}$. Thus, although this study analyzed a certain factory using rubber pads, the result can still be used to other high-tech buildings. We recommend that the numerical simulation be analyzed prior to construction, and then field experiments be performed to ensure that the vibration is reduced when the factory is built.

\section{Data Availability}

The data, such as building dimensions and numerical information, used to support the findings of this study are included within the article.

\section{Conflicts of Interest}

The authors declare that they have no conflicts of interest.

\section{References}

[1] P. Grootenhuis, "Floating track slab isolation for railways," Journal of Sound and Vibration, vol. 51, no. 3, pp. 443-448, 1977.

[2] J. Y. Choi, K. S. Hong, and K. J. Yang, "Exponential stabilization of an axially moving tensioned strip by passive damping and boundary control," Journal of Vibration and Control, vol. 10, no. 5, pp. 661-682, 2004.

[3] M. F. M. Hussein and H. E. M. Hunt, "Modelling of floatingslab tracks with continuous slabs under oscillating moving loads," Journal of Sound and Vibration, vol. 297, no. 1-2, pp. 37-54, 2006.

[4] Y. Dere, "Effectiveness of the floating slab track system constructed at Konya light rail," Measurement, vol. 89, pp. 48-54, 2016.

[5] X. Sheng, T. Zhong, and Y. Li, "Vibration and sound radiation of slab high-speed railway tracks subject to a moving harmonic load," Journal of Sound and Vibration, vol. 395, pp. 160-186, 2017. 
[6] T. X. Wu and D. J. Thompson, "The effects on railway rolling noise of wave reflections in the rail and support stiffening due to the presence of multiple wheels," Applied Acoustics, vol. 62, no. 11, pp. 1249-1266, 2001.

[7] M. H. Kargarnovin, D. Younesian, D. Thompson, and C. Jones, "Ride comfort of high-speed trains travelling over railway bridges," Vehicle System Dynamics, vol. 43, no. 3, pp. 173-197, 2005.

[8] S. Mirza, P. Hansen, and J. Harris, "Modelling and durability assessment for rubber components in rail vehicles," Plastics Rubber and Composites, vol. 40, no. 4, pp. 185-193, 2011.

[9] M. T. Tran, K. K. Ang, and V. H. Luong, "Vertical dynamic response of non-uniform motion of high-speed rails," Journal of Sound and Vibration, vol. 333, no. 21, pp. 5427-5442, 2014.

[10] L. Han, Y. Zhang, X. M. Li, L. H. Jiang, and D. Chen, "Flexural vibration reduction of hinged periodic beam-foundation systems," Soil Dynamics and Earthquake Engineering, vol. 79, pp. 1-4, 2015.

[11] C. Affolter, G. Piskoty, R. E. Koller, U. Gfeller, and G. P. Terrasi, "Limitations of analytical strength verifications with local effects and nonlinearities: a case study on a failed high rack rail," Engineering Failure Analysis, vol. 56, pp. 2838, 2015.

[12] M. Sol-Sanchez, F. Moreno-Navarro, and M. C. RubioGamez, "The use of elastic elements in railway tracks: a state of the art review," Construction and Building Materials, vol. 75, pp. 293-305, 2015.

[13] H. Jin, W. N. Liu, and S. H. Zhou, "An experiment to assess vibration reduction ability of the rubber floating-slab tracks with different supporting forms," Journal of Vibroengineering, vol. 17, no. 6, pp. 3237-3246, 2015.

[14] P. E. Gautier, "Slab track: review of existing systems and optimization potentials including very high speed," Construction and Building Materials, vol. 92, pp. 9-15, 2015.

[15] X. Y. Lei and C. D. Jiang, "Analysis of vibration reduction effect of steel spring floating slab track with finite elements," Journal of Vibration and Control, vol. 22, no. 6, pp. 1462-1471, 2016.

[16] I. A. Carrascal, J. A. Casado, S. Diego, and J. A. Polanco, "Dynamic behaviour of high-speed rail fastenings in the presence of desert sand," Construction and Building Materials, vol. 117, pp. 220-228, 2016.

[17] K. Wei, P. Zhang, P. Wang, J. H. Xiao, and Z. Luo, “The influence of amplitude- and frequency-dependent stiffness of rail pads on the random vibration of a vehicle-track coupled system," Shock and Vibration, vol. 2016, Article ID 7674124, 10 pages, 2016.

[18] L. Ling, J. Han, X. B. A. Xiao, and X. S. Jin, "Dynamic behavior of an embedded rail track coupled with a tram vehicle," Journal of Vibration and Control, vol. 23, no. 14, pp. 23552372, 2017.

[19] M. Oregui, A. Nunez, and R. Dollevoet, "Sensitivity analysis of rail pad parameters on vertical railway track dynamics," Journal of Engineering Mechanics, vol. 143, no. 5, article 04017011, 2017.

[20] S. H. Ju, "3D finite element analyses of wave barriers for reduction of train-induced vibrations," Journal of Geotechnical and Geoenvironmental Engineering, vol. 130, no. 7, pp. 740-748, 2004.

[21] F. T. K. Au, J. J. Wang, and Y. K. Cheung, "Impact study of cable-stayed railway bridges with random rail irregularities," Engineering Structures, vol. 24, no. 5, pp. 529-541, 2002. 


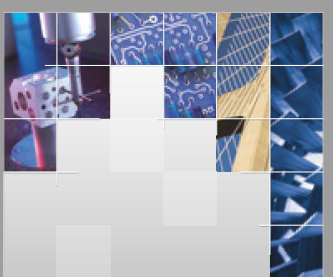

\section{Enfincering}
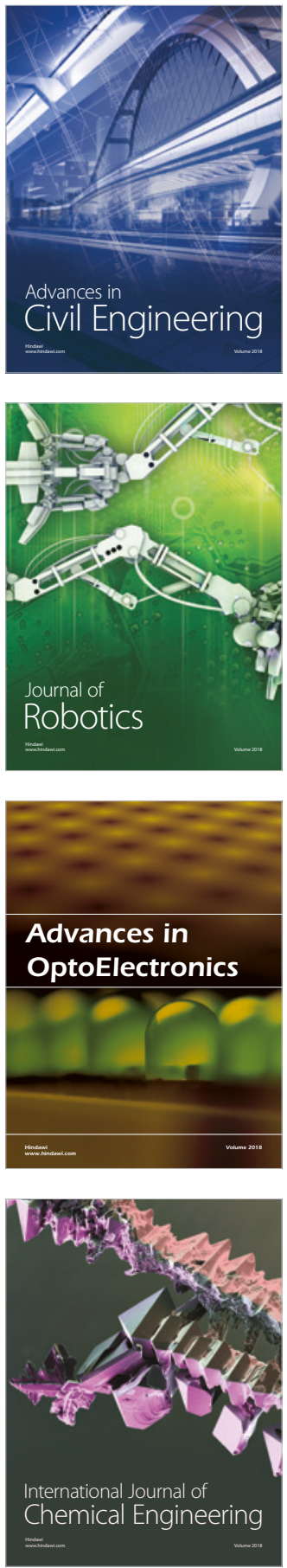

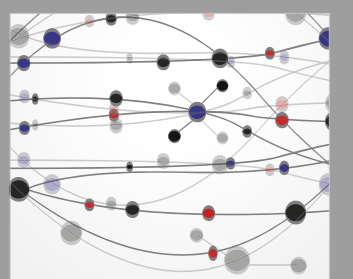

\section{Rotating \\ Machinery}

The Scientific World Journal

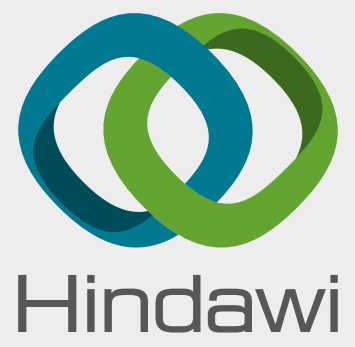

Submit your manuscripts at

www.hindawi.com
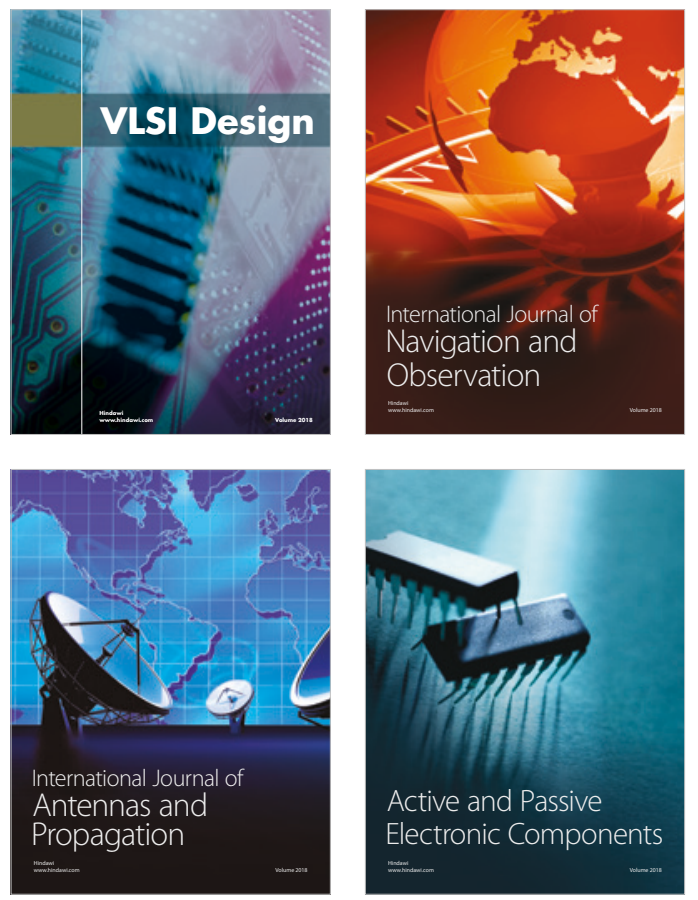
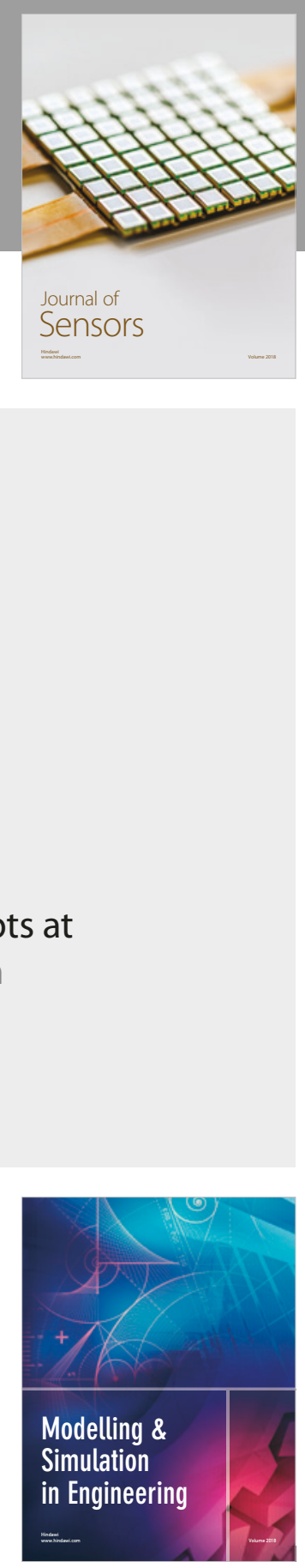

\section{Advances \\ Multimedia}
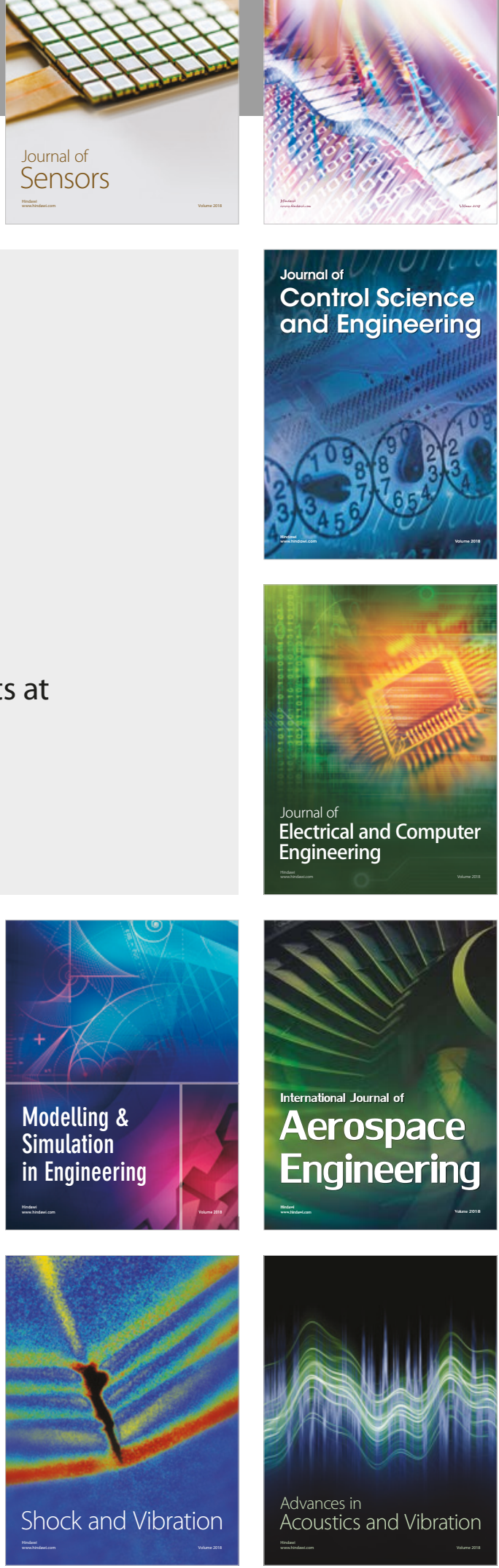